Article

\title{
Analysis of Operation Parameters in a Dual Fluidized Bed Biomass Gasifier Integrated with a Biomass Rotary Dryer: Development and Application of a System Model
}

\author{
Nargess Puadian, Jingge Li and Shusheng Pang * \\ Chemical and Process Engineering Department, University of Canterbury, Private Bag 4800, \\ Christchurch 8140, New Zealand; E-Mails: npu18@uclive.ac.nz (N.P.); \\ jingge.li@canterbury.ac.nz (J.L.) \\ * Author to whom correspondence should be addressed; E-Mail: Shusheng.pang@canterbury.ac.nz; \\ Tel.: +64-3-364-2538; Fax: +64-3-364-2063.
}

Received: 7 May 2014; in revised form: 22 June 2014 / Accepted: 2 July 2014 /

Published: 7 July 2014

\begin{abstract}
An integrated system model was developed in UniSim Design for a dual fluidized bed (DFB) biomass gasifier and a rotary biomass dryer using a combination of user-defined and built-in unit operations. A quasi-equilibrium model was used for modelling biomass steam gasification in the DFB gasifier. The biomass drying was simulated with consideration of mass and energy balances, heat transfer, and dryer's configuration. After validation using experimental data, the developed system model was applied to investigate: (1) the effects of gasification temperature and steam to biomass $(S / B)$ ratio on the gasification performance; (2) the effect of air supplied to the fast fluidized bed (FFB) reactor and feed biomass moisture content on the integrated system performance, energy and exergy efficiencies. It was found that gasification temperature and $S / B$ ratio have positive effects on the gasification yields; a $\mathrm{H}_{2} / \mathrm{CO}$ ratio of 1.9 can be achieved at the gasification temperature of $850^{\circ} \mathrm{C}$ with a $S / B$ ratio of 1.2. Consumption of excessive fuel in the system at higher biomass feed moisture content can be compensated by the heat recovery such as steam generation while it has adverse impact on exergy efficiency of the system.
\end{abstract}

Keywords: dual fluidized bed gasifier; biomass gasification; biomass drying; integrated system model; exergy efficiency 


\section{Introduction}

Dual fluidized bed (DFB) steam gasification has been proven to be a promising technology for converting biomass into a hydrogen-rich syngas for liquid fuel synthesis or for production of pure hydrogen for fuel cell applications [1]. A DFB gasification system reported in [1-4] consists of a bubbling fluidized bed (BFB) gasification reactor fluidized with steam as the gasification agent and a fast fluidized bed (FFB) combustion reactor fluidized with air for char combustion. In the DFB biomass gasification, the biomass is fed into the bed layer of BFB reactor where steam gasification occurs. Char generated from the gasification flows with circulating bed material to FFB reactor where it is combusted. The circulating bed material such as silica sand or olivine carries heat from the FFB reactor to the $\mathrm{BFB}$ reactor for endothermic gasification reactions. A controlled amount of excessive fuel may be added to provide sufficient heat to achieve target gasification temperature in the BFB reactor. The gasification process produces a hydrogen-rich producer gas with much higher calorific value of approximately $13 \mathrm{MJ} / \mathrm{Nm}^{3}$ compared with that from air gasification, which is approximately $5 \mathrm{MJ} / \mathrm{Nm}^{3}$ [1]. It is also able to produce a syngas with a $\mathrm{H}_{2} / \mathrm{CO}$ ratio of 2 desired for Fischer-Tropsch (FT) synthesis of transport fuels [4].

For efficient gasification in the DFB gasifier, woody biomass feedstock is normally in the form of pellets or chips. The pellets have particle size of $6-15 \mathrm{~mm}$ and moisture content of around $10 \%$ (oven dry basis) while for the wood chips, the preferred particle size is from 2 to $30 \mathrm{~mm}$ and the required moisture content is normally less than $20 \%$ [2,5]. However, fresh woody biomass usually has high moisture content of $50 \%-60 \%$ [6] and, in this case, drying of the feedstock is necessary as a pre-treatment procedure in an industrial gasification plant. A rotary dryer is identified as the most suitable equipment for drying of biomass in a full scale biomass gasification plant [7].

In the DFB biomass gasification system, flue gas is clean and thus its sensible heat can be used for biomass drying. Furthermore, the sensible heat of producer gas and flue gas from the DFB gasification can be recovered to generate steam required in the gasification system and to preheat the air supplied to the FFB reactor. Integration of the DFB gasifier with the rotary dryer will increase the overall efficiency and potentially optimize the system operation. Begum et al. [8,9] studied the integration of biomass drying with fixed bed and fluidized bed gasification; however, no publication has been found in literature on DFB gasification-drying integration modelling.

Recently, exergy has attracted interest from researchers for system analysis. Although the advantages of using exergy has been well known, no studies have been found on the exergy analysis of the DFB biomass steam gasification system integrated with the biomass drying. The energy and exergy analysis of woody biomass drying were conducted by Holmberg and Ahtila [10] through heat consumption of drying and irreversibility rate occurs in drying for both single stage and multi stage drying systems with different drying mediums. They concluded that while heat consumption is similar in different systems, the irreversibility rate depends on the system configuration and temperature of the drying medium. Vitasari et al. [11] conducted an exergy analysis on biomass to synthetic natural gas via DFB biomass gasification system. However, their focus was on a methanation reactor rather than DFB biomass gasification. In their study, biomass drying was assumed as a pretreatment step and was limited to feed biomass moisture content of $30 \%$ or less. The other integrated systems including entrained flow gasifiers and fluidized bed gasifiers were studied by Bechtel [12], Tijmensen et al. [13] 
and Swanson et al. [14]. In these studies, the dryer was considered but the drying medium was the preheated air and steam. Furthermore, these studies focused on economic analysis rather than energy consumption and process performance.

The performance of biomass drying was studied in a number of publications by application of mathematical models, some being very complicated and others quite simple. The complex models were based on detailed mass and heat transfer which occurs both between the drying medium and the solid material and within the solid material [15]. The simple models were based on the overall mass and heat balances of the system employing empirical equations or parameters for the drying rates [7].

Numerous publications can also be found in literature on fundamental studies of biomass gasification systems either by developing complex kinetic rate and neural network models or by application of simple equilibrium models [16-19]. Ngo et al. and Nguyen et al. [19,20] extensively studied the performance of DFB biomass gasification system by developing a "quasi equilibrium model". For improving the conventional equilibrium model, the quasi-equilibrium model is adopted in which a number of justification factors are introduced based on experimental results. The objectives of the present work were to develop an integrated system model for DFB biomass gasification and biomass drying and to investigate the effects of operation parameters on the system performance. These parameters include gasification temperature, steam to biomass $(S / B)$ ratio, feed air to the FFB reactor and initial moisture content of the feed biomass.

\section{Model Development}

The integrated system model for biomass drying and biomass gasification has been developed with professional simulation software, UniSim (Honeywell International Inc., Phoenix, AZ, USA), which includes conventional unit operations, components and thermodynamic packages necessary for modelling a system. In addition, the software also has capability for users to define new unit operations or components which are not included in the software.

For modelling of the rotary drying, a user-defined unit operation has been developed based on mass and energy balances. For modelling of the DFB gasification system, both of the gasification process in the BFB reactor and the combustion process in the FFB reactor have been considered. In the BFB gasification process, a three stage quasi equilibrium model has been proposed which includes initial pyrolysis, subsequent reactions between char and gases and reactions among gases.

\subsection{Woody Biomass Characteristics}

In the present study, chips of Pinus radiata wood are used as the feedstock which chemical formula is assumed to be $\mathrm{C}_{31} \mathrm{H}_{45} \mathrm{O}_{24.5}$ with the proximate and ultimate analysis listed in Table 1 [17]. The lower heating value $(L H V)$ of biomass $(\mathrm{kJ} / \mathrm{kg})$, water and ash free basis, was calculated using the following correlation [21]:

$$
L H V_{\text {biom }}=34,835 z_{\mathrm{C}}+93,870 z_{\mathrm{H}}-10,800 z_{\mathrm{O}}+6280 z_{\mathrm{N}}+10,465 z_{\mathrm{S}}
$$

In which, $z_{i}$ is the mass fraction of elements of carbon $(\mathrm{C})$, hydrogen $(\mathrm{H})$, oxygen $(\mathrm{O})$, nitrogen $(\mathrm{N})$, and sulfur (S). 
The thermal and physical properties of Pinus radiata are determined as a hypothetical compound in the UniSim. The heat of formation of the feedstock is calculated from the combustion reaction, Equation (2), and the heat capacity $\left(\mathrm{kJ} / \mathrm{kg} \cdot{ }^{\circ} \mathrm{C}\right)$ of moisture free feedstock is calculated using Equation (3) taken from [22]:

$$
\begin{gathered}
\mathrm{C}_{31} \mathrm{H}_{45} \mathrm{O}_{24.5}+30 \mathrm{O}_{2} \rightarrow 31 \mathrm{CO}_{2}+22.5 \mathrm{H}_{2} \mathrm{O} \\
C p_{\text {biom }}=0.1031+0.003867 T
\end{gathered}
$$

where $T$ is the temperature $(\mathrm{K})$.

Table 1. Proximate and ultimate analysis results of Pinus radiata [17].

\begin{tabular}{cccc}
\hline \multicolumn{2}{c}{ Proximate Analysis wt\% (od) } & \multicolumn{2}{c}{ Ultimate Analysis, wt\% (od) } \\
\hline $\mathrm{H}_{2} \mathrm{O}$ & 0 & $\mathrm{C}$ & 51.2 \\
Volatile & 84 & $\mathrm{H}$ & 6.1 \\
Fixed carbon & 15.6 & $\mathrm{O}$ & 42.3 \\
Ash & 0.4 & $\mathrm{~N}$ & 0.2 \\
- & - & $\mathrm{S}$ & 0.02 \\
\hline
\end{tabular}

\subsection{Process Configuration}

The process configuration is shown in Figure 1 in which the wood chips firstly enter the rotary dryer where they are dried to a target moisture content of $15 \%$. The dried biomass then goes to the $\mathrm{BFB}$ reactor for steam gasification. The producer gas from the gasifier is cooled down in a heat recovery boiler to around $340{ }^{\circ} \mathrm{C}$ for the subsequent gas cleaning [23]. In the boiler, the sensible heat of the producer gas is recovered for generation of steam which is used in the BFB reactor for biomass steam gasification.

The hot flue gas from the FFB reactor has a temperature ranging from 850 to $950{ }^{\circ} \mathrm{C}$ which is used firstly for air preheating followed by steam generation and finally for the biomass drying. In normal operation, the temperature in the FFB reactor is $50-100^{\circ} \mathrm{C}$ higher than the gasification temperature in the $\mathrm{BFB}$ reactor to provide the heat required for the gasification process.

In the modeling of the integrated biomass drying and DFB gasification, the water and steam balance needs to consider the moisture content of the biomass to the dryer and the steam to the biomass ratio to the gasifier. In the meantime, biomass moisture content also affects the heat required for biomass drying which, in turn, affects the heat available for generation of steam.

There are four streams of water into the system or generated in the system: the feed biomass moisture, the air humidity, the water injected to the system for steam generation, and reaction water which forms during combustion and gasification reactions. As is shown in Figure 1, the flue gas from the FFB reactor after air preheating, steam generation and biomass drying is released to the atmosphere as exhaust gas. Air preheating and steam generation are indirect processes while biomass drying is a direct process where flue gas and biomass are in direct contact. Therefore, the water in the exhaust gas is from air humidity, excessive fuel combustion and vaporization of feed biomass moisture during drying. The source of steam generated in the system is from the water imported to the system. 
The water in the producer gas is from the steam injected to the BFB reactor, the water vapourised from biomass and gasification reactions.

Figure 1. Process diagram of the integrated system of biomass drying and dual fluidized bed (DFB) biomass gasification.

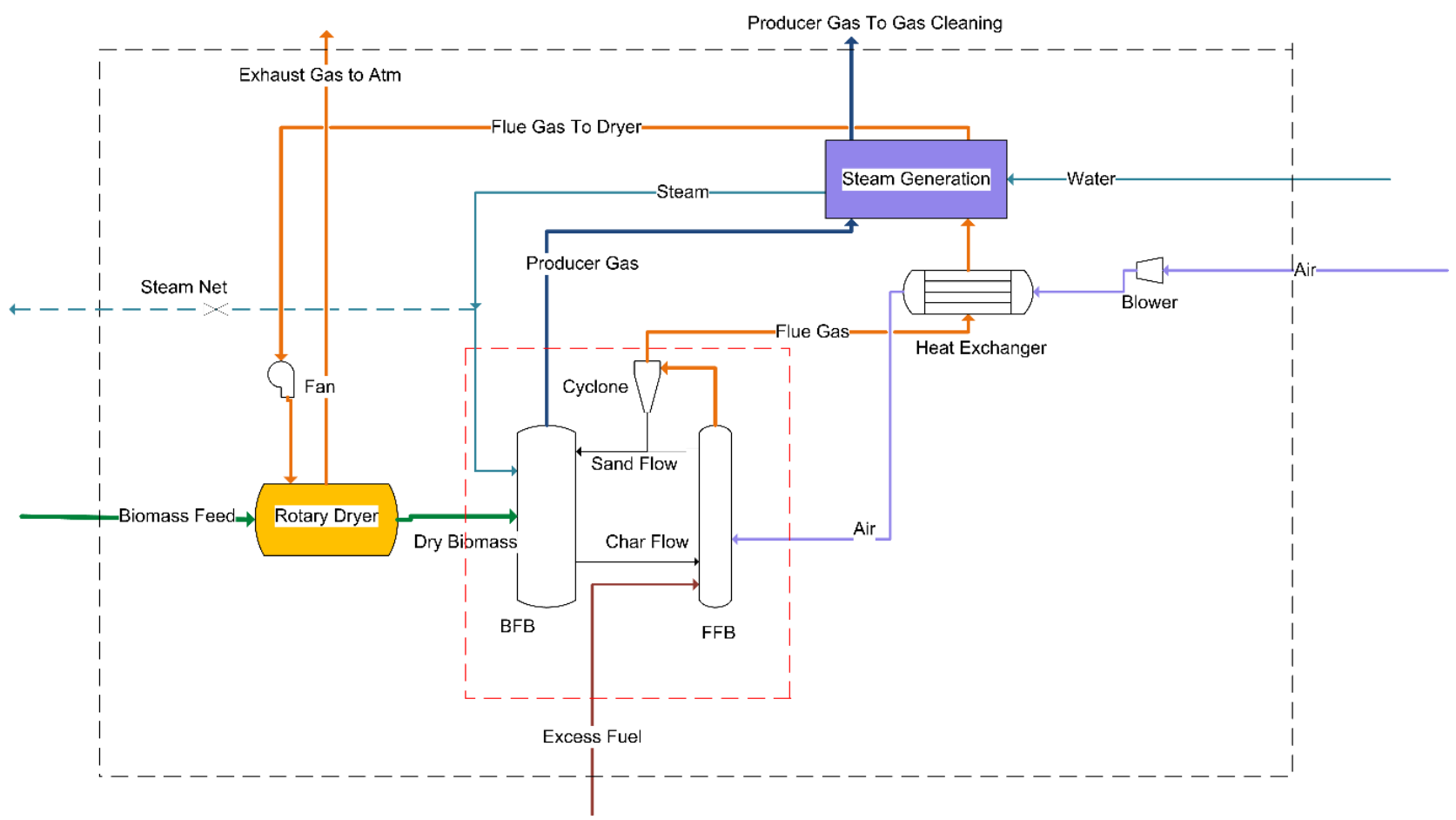

\subsection{Modelling of the Rotary Drying}

An overview of the rotary dryer's model is shown in Figure 2. The feedstock is assumed to be from forest residues or from green log processing, therefore, the original moisture content is estimated to be between $50 \%$ and $60 \%$. A rotary dryer was selected for biomass drying because it is relatively simple and flexible for using different types and sizes of biomass feedstock [6]. Co-current configuration is adopted for the rotary drying, which prevents direct contact between hot drying medium and the dry biomass thereby lower potential fire hazard [6]. In modeling the biomass drying, the following assumptions were made:

- The temperature of the biomass and the drying medium at the outlet of the dryer is very close. Rigorous modeling results have shown that the temperature difference at the dryer outlet in co-current rotary dryer is insignificant when the final moisture content is less than $15 \%[7,24]$.

- The exhaust gas temperature is assumed to be always higher than wet-bulb temperature $\left(70{ }^{\circ} \mathrm{C}\right)$.

- The heat of vaporization of water is kept constant during the drying using the average temperature between inlet and outlet temperatures.

- The heat loss of the dryer is assumed to be $15 \%$ based on the experimental results with a semi industrial rotary dryer [25]. It does not include the heat loss by the exhaust gas.

- The heat transfer coefficient between the drying medium and the biomass is calculated using the correlation proposed by Saeman and Mitchell [26]. 
The calculation of actual biomass drying rate can be complicated, which involves heat and mass transfer both within the solid biomass and between the biomass surface and the drying medium. As the final moisture content in this study is relatively high (15\%), the drying rate is still reasonably fast at the end of drying, and thus the drying process is largely controlled by the heat transfer rate. The correlation of Saeman and Mitchel was used for calculating the dryer's dimensions [26]. The overall mass and heat balance equations for both the biomass and the flue gas was developed in a user-defined unit operation in UniSim in this study following the procedure presented in [27].

Figure 2. An overview of the rotary dryer model.

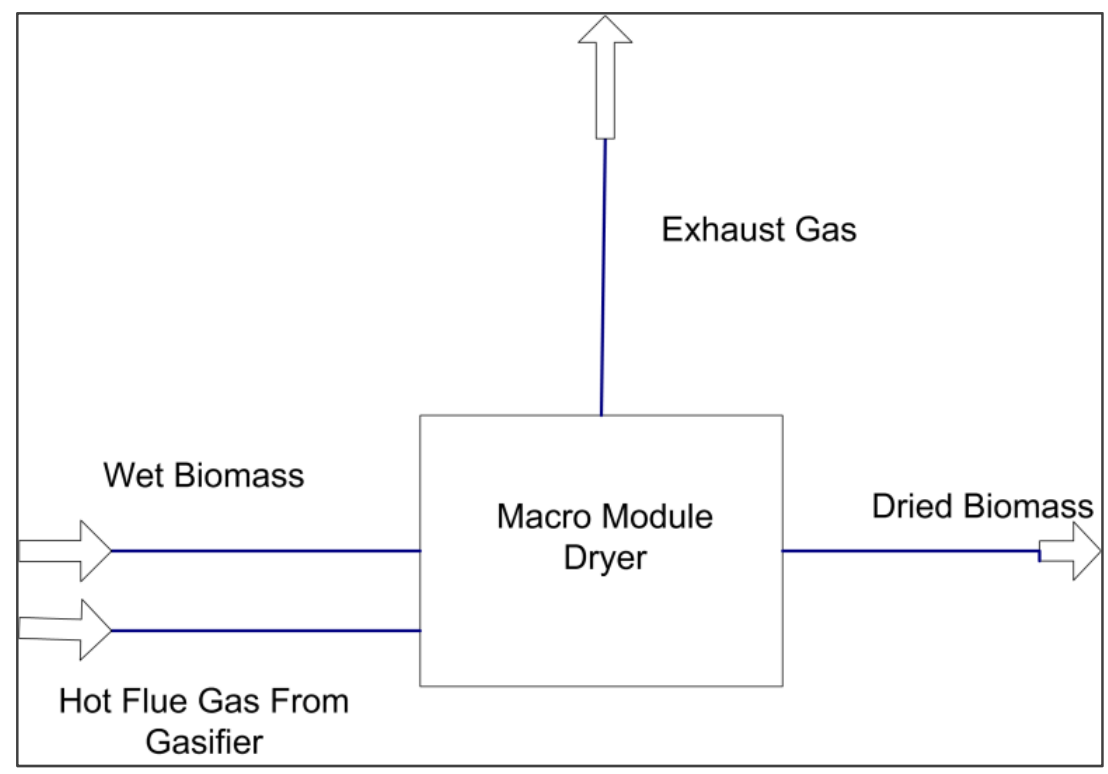

\subsubsection{Mass Balance of Water}

The overall mass balance for the water over the dryer is relatively simple because there is no chemical reaction involved in the process and the water is the only component transferring between phases. The water lost by the feed biomass is gained by the gas phase, as is described in Equation (4):

$$
\dot{M}_{\mathrm{fg}}\left(Y_{2}-Y_{1}\right)=\dot{M}_{\text {biom }}\left(X_{1}-X_{2}\right)
$$

where $\dot{M}_{\mathrm{fg}}$ and $\dot{M}_{\text {biom }}$ are the mass flow rate of the flue gas and the biomass on dry basis, $(\mathrm{kg} / \mathrm{s})$ and $Y_{1}$ and $Y_{2}$ are the inlet and the outlet humidity of the flue gas, $(\mathrm{kg} / \mathrm{kg}) . X_{1}$ and $X_{2}$ are inlet and outlet moisture contents of the biomass, $(\mathrm{kg} / \mathrm{kg})$, which are calculated from Equation (5):

$$
X=M C /(100-M C)
$$

where $M C$ is the feed biomass moisture content, \%. The humidity and mass flow rate of the inlet flue gas were determined from the gasifier unit operation which is described in Section 2.4. Therefore, if the inlet and target moisture content of the biomass are known, the outlet humidity of flue gas can be determined from Equation (4). 


\subsubsection{Energy Balance}

The energy balance of the drying system is based on the consideration that the heat provided by the flue gas $(Q)$ is equal to the heat gained by the biomass for heat-up and for water vaporization plus the heat loss $(15 \%)$ :

$$
Q=Q_{1}+Q_{2}+Q_{3}+Q_{4}+Q_{5}+Q_{L}
$$

In which:

$$
Q=\left(\dot{M}_{\mathrm{fg}} C p_{\mathrm{fg}}+\dot{M}_{\mathrm{fg}} Y_{1} C p_{v w}\right)\left(T_{\mathrm{fg}}-T_{\text {out }}\right)
$$

$Q_{1}$ is the heat for the feed (moist biomass) to be heated to the wet bulb temperature:

$$
Q_{1}=\left(\dot{M}_{\text {biom }} C p_{\text {biom }}+\dot{M}_{\text {biom }} X_{1} C p_{v w}\right)\left(T_{w}-T_{b}\right)
$$

$Q_{2}$ is the heat for the water vaporization at the wet-bulb temperature:

$$
Q_{2}=\dot{M}_{\text {biom }}\left(X_{1}-X_{2}\right) \Delta H_{v w}
$$

$Q_{3}$ is the heat for the biomass to be heated to the outlet temperature:

$$
Q_{3}=\dot{M}_{\text {biom }} C p_{\text {biom }}\left(T_{\text {out }}-T_{w}\right)
$$

$Q_{4}$ is the heat used to heat the remaining moisture in the biomass to the outlet temperature:

$$
Q_{4}=\dot{M}_{\text {biom }} X_{2} C p_{l w}\left(T_{\text {out }}-T_{w}\right)
$$

$Q_{5}$ is the heat used to heat the water vapour to the outlet temperature:

$$
Q_{5}=\dot{M}_{\text {biom }}\left(X_{1}-X_{2}\right) C p_{v w}\left(T_{\text {out }}-T_{w}\right)
$$

$Q_{L}$ is the heat loss and estimated by:

$$
Q_{L}=0.15 Q
$$

In the above equations, $T_{\mathrm{fg}}$ and $T_{b}$ are the inlet temperatures of the flue gas and biomass respectively; $T_{\text {out }}$ is the outlet temperature of the dryer $\left({ }^{\circ} \mathrm{C}\right) ; T_{w}$ is the wet-bulb temperature of the flue gas $\left({ }^{\circ} \mathrm{C}\right) . \Delta H_{v w}$ is the latent heat of vaporization of water $(\mathrm{kJ} / \mathrm{kg})$ at $T_{w} . C p_{\mathrm{fg}}, C p_{\text {biom }}, C p_{l w}$ and $C p_{v w}$ are the specific heat of, respectively, flue gas, biomass, liquid water, and vapour water $\left(\mathrm{kJ} / \mathrm{kg}{ }^{\circ} \mathrm{C}\right)$ which are taken as constants during drying.

\subsection{Modelling of the Gasification System}

The biomass steam gasification process is modeled in three stages including pyrolysis, char-gas reactions and reactions among gases [19,28,29]. A "quasi three stage equilibrium model" was adopted from [20] with some adjustments. For the pyrolysis step, a macro code was written in a user defined unit operation in UniSim. For char-gas reactions, a Gibbs reactor was modeled to calculate their equilibrium with limited steam contribution. For reactions among gases, a limited steam-gas shift reaction was modeled in an equilibrium reactor. For modeling the FFB reactor, a conversion reactor was defined for combustion of un-reacted char and excessive fuel. An overview of the DFB gasifier model developed in UniSim is shown in Figure 3. 
Figure 3. An overview of the DFB gasifier model developed in UniSim Design.

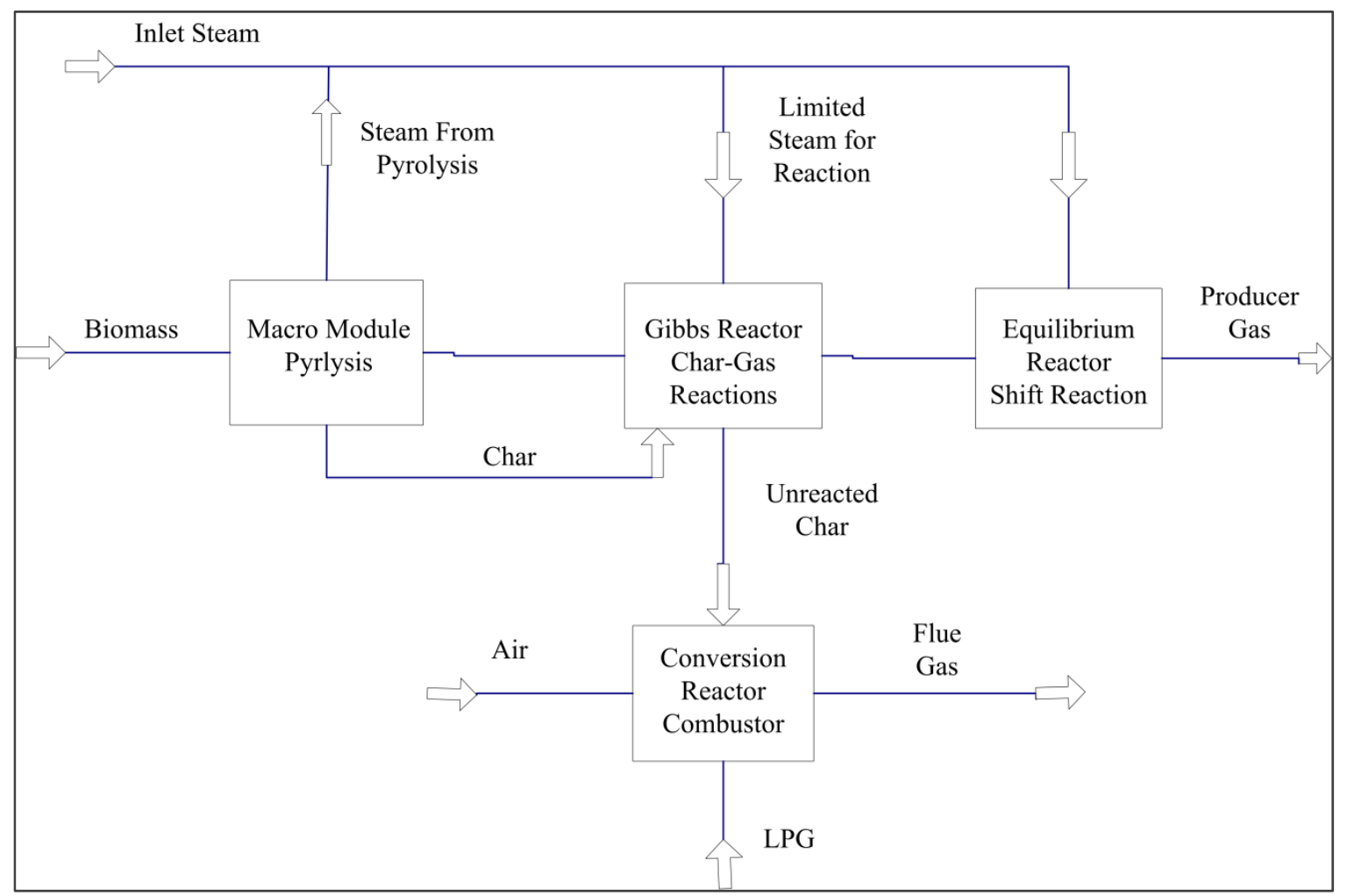

\subsubsection{Modeling of the Pyrolysis Step}

In the pyrolysis step, biomass is converted to a mixture of char and combustible gases. The precise prediction of the pyrolysis products is regarded as the most important stage of the gasification [19]. The pyrolysis gas mainly consists of $\mathrm{H}_{2}, \mathrm{CO}, \mathrm{CO}_{2}, \mathrm{H}_{2} \mathrm{O}, \mathrm{CH}_{4}, \mathrm{~N}_{2}, \mathrm{NH}_{3}, \mathrm{H}_{2} \mathrm{~S}$ and tar vapors. By introduction of two empirical factors of $\Phi_{\mathrm{CO}}$ (molar ratio of $\mathrm{CO} / \mathrm{CO}_{2}$ ) and $\Phi_{\mathrm{CH} 4}$ (molar ratio of $\mathrm{CH}_{4} / \mathrm{H}_{2}$ ), five equations were generated based on elemental balances of $\mathrm{C}, \mathrm{H}$ and $\mathrm{O}$ components of the biomass and the gas to calculate the concentration of the five major components of the gas including $\mathrm{H}_{2}, \mathrm{CO}, \mathrm{CO}_{2}, \mathrm{H}_{2} \mathrm{O}$ and $\mathrm{CH}_{4}$. In the modeling, methane also represents traces of other light hydrocarbons and tar:

$$
\begin{gathered}
n_{\mathrm{CO}}+n_{\mathrm{CO}_{2}}+n_{\mathrm{CH}_{4}}=n_{\mathrm{C}} \\
4 n_{\mathrm{CH}_{4}}+2 n_{\mathrm{H}_{2}}+2 n_{\mathrm{H}_{2} \mathrm{O}}=n_{\mathrm{H}} \\
n_{\mathrm{CO}}+2 n_{\mathrm{CO}_{2}}=n_{\mathrm{O}} \\
n_{\mathrm{CO}}-\Phi_{\mathrm{CO}_{\mathrm{CO}_{2}}}=0 \\
n_{\mathrm{CH}_{4}}-\Phi_{\mathrm{CH}_{4}} n_{\mathrm{H}_{2}}=0
\end{gathered}
$$

where, $n_{i}$ is the molar flow rate of each component $(\mathrm{kmol} / \mathrm{s})$. $\Phi_{\mathrm{CO}}$ and $\Phi_{\mathrm{CH}_{4}}$ are determined by the following correlations as a function of temperature:

$$
\Phi_{\mathrm{CO}}=A_{1} \times \exp \left(-B_{1} / T_{g}\right)
$$




$$
\Phi_{\mathrm{CH}_{4}}=1.4 \times A_{2} \times \exp \left(-B_{2} / T_{g}\right)
$$

where $T_{g}$ is the gasification temperature $(\mathrm{K}), A_{1}=4.7 \times 10^{3}, B_{1}=7163.6, A_{2}=2.28 \times 10^{-3}$ and $B_{2}=5404.85$ which were obtained from curve fitting of the experimental data reported in [30].

The amount and composition of tar may change significantly from pyrolysis step to final gasification [31]. However, in this study, this transition was ignored and the final tar content of producer gas (dry basis) was assumed as a function of gasification temperature, Equation (21), which was adopted from the experimental data reported in [32]. Then, the composition of methane was modified by subtracting the carbon and hydrogen content of tar which its composition was taken from [1]:

$$
\operatorname{Tar}(\mathrm{wt} \%)=-5.61 \times 10^{-3} \times T_{g}(\mathrm{~K})+6.95
$$

The concentrations of other species $\left(\mathrm{N}_{2}, \mathrm{NH}_{3}\right.$ and $\left.\mathrm{H}_{2} \mathrm{~S}\right)$ were calculated from the elemental balances for $\mathrm{N}$ and $\mathrm{S}$ and their formation reactions. The composition of hydrogen was also modified by subtracting the hydrogen content of ammonia and hydrogen sulfide.

\subsubsection{Modeling of the Char-gas Reactions and Reactions among Gases}

In this study, Boudouard, primary and secondary steam-gas reactions were assumed as the char-gas reactions while steam-gas shift reaction was assumed as the steam-gas reaction [28]:

- Boudouard: $\mathrm{C}+\mathrm{CO}_{2} \rightarrow 2 \mathrm{CO}$

- Primary steam-gas reaction: $\mathrm{C}+\mathrm{H}_{2} \mathrm{O} \rightarrow \mathrm{CO}+\mathrm{H}_{2}$

- Secondary steam-gas reaction: $\mathrm{C}+2 \mathrm{H}_{2} \mathrm{O} \rightarrow \mathrm{CO}_{2}+2 \mathrm{H}_{2}$

- Steam-gas shift reaction: $\mathrm{CO}+\mathrm{H}_{2} \mathrm{O} \rightarrow \mathrm{CO}_{2}+\mathrm{H}_{2}$

It has been shown that steam contribution to the primary and secondary steam-gas reactions is limited [33,34]; therefore, the steam contribution to reactions at equilibrium can be calculated using a simple correlation as follows[20]:

$$
\alpha=\frac{n_{\mathrm{H}_{2} \mathrm{O}, \mathrm{con}}}{n_{\mathrm{H}_{2} \mathrm{O}}}=51.4 \exp \left(-7542.8 / T_{g}\right)
$$

where $n_{\mathrm{H}_{2} \mathrm{O}}$ is the total moles of steam in the system, $n_{\mathrm{H} 2 \mathrm{O} \text {, con }}$ is the moles of steam that contributes to the reactions and $T_{g}$ is the gasification temperature $(\mathrm{K})$.

In order to check the equilibrium assumption of steam-gas shift reaction, the equilibrium constant of this reaction has been compared with the reaction constants derived from experimental results of Herguido et al. [35] and Wei et al. [36] and the results are shown in Figure 4. The average value of their results for the steam-gas shift reaction constant was used in the present model in UniSim. 
Figure 4. The steam-gas shift reaction equilibrium constant at different temperatures.

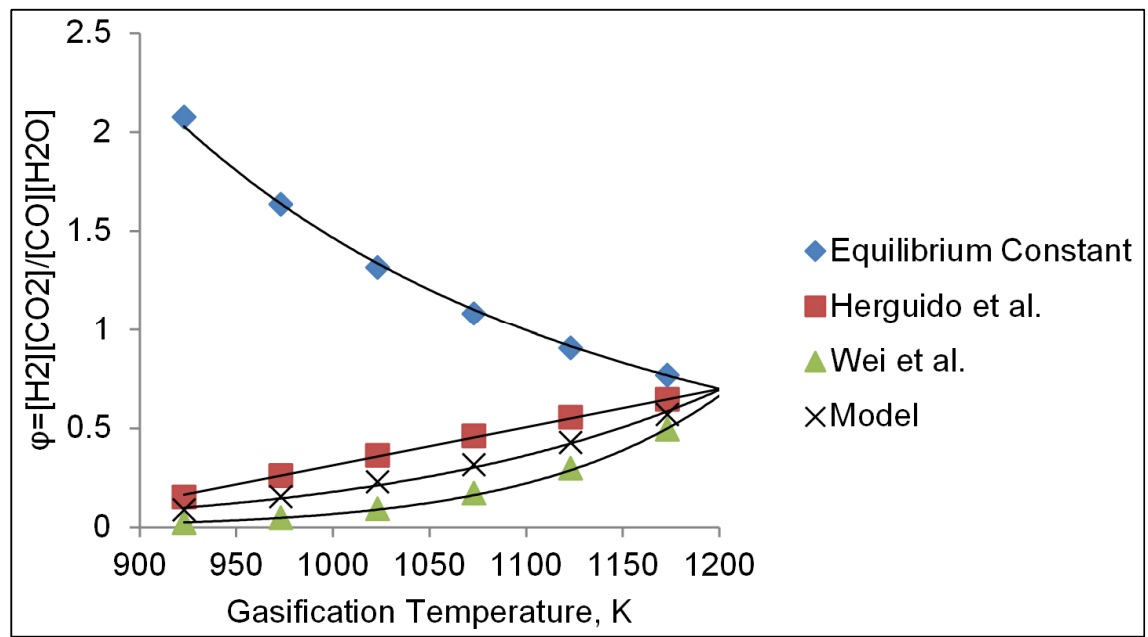

The heat requirement of the BFB gasification reactor is the sum of the heat requirement of pyrolysis, char-gas reactions and steam-gas reaction sections. The heat requirement of each part was calculated from the enthalpy balance in UniSim. The char generated from the biomass gasification and the excessive fuel to the FFB reactor are combusted with air supplied to provide the energy required for the BFB gasification reactor. In a commercial scale DFB gasifier (100 MW), the heat loss can be reduced and, in the present study, heat loss is assumed to be $5 \%$ of biomass energy $\left(L H V_{\text {biom }} \times \dot{M}_{\text {biom }}\right)$. The excessive fuel to the FFB reactor is represented by the ratio of the excessive fuel energy supply to the feed biomass energy:

$$
\omega=\dot{M}_{\text {fuel }} \times L H V_{\text {fuel }} / \dot{M}_{\text {biom }} \times L H V_{\text {biom }}
$$

where $\dot{M}_{\text {fuel }}$ and $\dot{M}_{\text {biom }}(\mathrm{kg} / \mathrm{s})$ are the mass flow of the excessive fuel and biomass, respectively, and $L H V_{\text {fuel }}$ and $L H V_{\text {biom }}(\mathrm{MJ} / \mathrm{kg})$ are the corresponding lower heating values.

The amount of air supplied to the FFB reactor is important in any simulation of the DFB biomass gasification system. The purpose of air supplied to the FFB reactor is for oxidizing the char and excessive fuel as well as acting as fluidizing agent. The excessive factor for air supply $(\lambda)$ is taken into account which is defined as:

$$
\lambda=\dot{M}_{\text {air }} / \dot{M}_{\text {air,stoich }}
$$

where $\dot{M}_{\text {air }}(\mathrm{kg} / \mathrm{s})$ is the mass flow rate of air supply to the FFB reactor and $\dot{M}_{\text {airstoich }}(\mathrm{kg} / \mathrm{s})$ is the mass flow rate of air at stoichiometric condition.

\subsection{Energy and Exergy Efficiencies of an Integrated System}

The exergy of a system at a given condition is the maximum amount of useful work which can be extracted from the system in that environment. For calculating the exergy efficiency of an integrated system; there are two approaches. In one approach, the system is assumed as a black box and exergy efficiency is calculated as the ratio of total exergy of useful product to the total exergy input [11,37]. In another approach, the role of individual unit operations in total exergy efficiency of the integrated 
system is determined [38,39] which is used in this study. Based on this approach, the overall exergy efficiency of the system is calculated from the following equation:

$$
\eta_{e x}=\left(\sum^{m} E \dot{x}_{u, i}-\sum^{n} \dot{I}_{j}\right) / \sum^{m+n} E \dot{x}_{a, k}
$$

where, $m$ and $n$ represents the numbers of head and non-head unit operations. A head unit operation exchanges the energy streams with the environment while a non-head unit operation does not. $\dot{E} x_{u, i}$, is the useful exergy of unit operation $i ; \dot{I}_{j}$ is the internal exergy loss of unit operation $j ; \dot{E x}_{a, k}$ is the available exergy of each unit operation. The internal exergy loss is calculated from the following equation:

$$
\dot{I}=E \dot{x}_{a}-E \dot{x}_{u}
$$

Based on the process flow diagram shown in Figure 1 and the classification of unit operations reported in [38], the useful and available exergy of each unit operation is listed in Table 2.

Table 2. The available and useful exergy of each unit operation.

\begin{tabular}{ccc}
\hline Item & $E \dot{x}_{a}$ & $E \dot{x}_{u}$ \\
\hline Biomass Drying & $E \dot{x}_{\mathrm{fg}, \text { in }}-E \dot{x}_{\mathrm{fg}, \text { out }}$ & 0 \\
Air Preheating & $E \dot{x}_{\mathrm{fg}, \text { in }}-E \dot{x}_{\mathrm{fg}, \text { out }}$ & $E \dot{x}_{\text {air,out }}-E \dot{x}_{\text {air,in }}$ \\
Steam Generation & $\left(E \dot{x}_{\mathrm{fg}, \text { in }}+E \dot{x}_{\mathrm{pg}, \text { in }}\right)-\left(E \dot{x}_{\mathrm{fg}, \text { out }}+E \dot{x}_{\mathrm{fg}, \text { out }}\right)$ & $E \dot{x}_{\text {steam, gen }}$ \\
DFB Gasification & $E \dot{x}_{\text {biom }}+E \dot{x}_{\text {fuel }}$ & $\left(E \dot{x}_{\mathrm{pg}}+E \dot{x}_{\mathrm{fg}}\right)-\left(E \dot{x}_{\text {air }}+E \dot{x}_{\text {steam,on }}\right)$ \\
Blower & $E l_{\text {power }}$ & $E \dot{x}_{\text {air,out }}-E \dot{x}_{\text {air,in }}$ \\
Fan & $E l_{\text {power }}$ & $E \dot{x}_{\text {fg,out }}-E \dot{x}_{\text {fg,in }}$ \\
\hline
\end{tabular}

The following equation for total exergy efficiency of the system is achieved from Equation (25) and relations presented in Table 2:

$$
\eta_{\mathrm{ex}}=\left(\dot{M}_{\mathrm{pg}} \times E x_{\mathrm{ch,pg}}+E \dot{x}_{\text {steam,exp }}\right) /\left(\dot{M}_{\text {biom }} \times E x_{\text {ch,biom }}+\dot{M}_{\text {fuel }} \times E x_{\text {ch,fuel }}+E \dot{x}_{\text {steam,imp }}+E l_{\text {power }}\right)
$$

where $E x_{\mathrm{ch}, \mathrm{pg}}, E x_{\mathrm{ch}, \mathrm{biom}}$ and $E x_{\mathrm{ch}, f u e l}, \mathrm{MJ} / \mathrm{kg}$, are the chemical exergy of producer gas, biomass and excessive fuel, respectively. $\dot{M}_{\mathrm{pg}}, \dot{M}_{\text {biom }}$ and $\dot{M}_{\text {fuel }}, \mathrm{kg} / \mathrm{s}$, are correspondingly the mass flow rate of producer gas, biomass and excessive fuel. $\dot{E} x_{\text {steam,exp }}$ and $\dot{E} x_{\text {steam,imp }}$ are the exergy of imported and exported steams, $M W_{\text {th }} E l_{\text {power, }}$ is the electrical power, MW. Chemical exergy of the producer gas was calculated from following relation adopted from [40]:

$$
E x_{\mathrm{ch}, \mathrm{pg}}=1 /\left(1000 \times M w_{\mathrm{pg}}\right) \times\left[y_{i} E x_{\mathrm{ch}, i}^{0}+R T_{0} \sum y_{i} \operatorname{Ln}\left(y_{i}\right)\right]
$$

In which, $M w_{\text {pg }}$ is the molecular weight of producer gas, $\mathrm{kg} / \mathrm{kmol} ; y_{i}$ is the mole fraction of producer gas components; $E x_{\mathrm{ch}, i}^{0}$ is the standard chemical exergy of each component, $\mathrm{kJ} / \mathrm{kmol} ; T_{0}$ is the environment temperature, $\mathrm{K} ; R$ is the gas universal constant, $8.314 \mathrm{~kJ} / \mathrm{kmol} \cdot \mathrm{K}$. The chemical exergy of woody biomass is related to its lower heating value $\left(E x_{\text {ch,biom }}=\beta \times L H V_{\text {biom }}\right)$ where $\beta$ was calculated from following relation [40]:

$$
\beta=\frac{\left(1.0412+0.2160 z_{\mathrm{H}} / z_{\mathrm{C}}+0.2499 z_{\mathrm{O}} / z_{\mathrm{C}}\left(1+0.7884 z_{\mathrm{H}} / z_{\mathrm{C}}\right)+0.0450 z_{\mathrm{N}} / z_{\mathrm{C}}\right)}{1+0.3035 z_{\mathrm{O}} / z_{\mathrm{C}}}
$$


where $z_{i}$ is the mass fraction of each element of of carbon $(\mathrm{C})$, hydrogen $(\mathrm{H})$, oxygen $(\mathrm{O})$, nitrogen $(\mathrm{N})$, and sulfur (S). The standard chemical exergy of producer gas components, water and excessive fuel which is assumed as liquid petroleum gas (LPG) in this study were obtained from [40]. The exergy of imported/exported steam is calculated from following relations:

$$
\begin{aligned}
E \dot{x}_{\text {steam,imp/exp }} & =\left|E \dot{x}_{\text {steam,gen }}-E \dot{x}_{\text {steam,con }}\right| \\
E \dot{x}_{\text {steam }} & =\dot{Q}_{\text {steam }}\left(1-T_{0} / T\right) \\
\dot{Q}_{\text {steam }} & =\dot{M}_{\text {steam }}\left(h-h_{0}\right)
\end{aligned}
$$

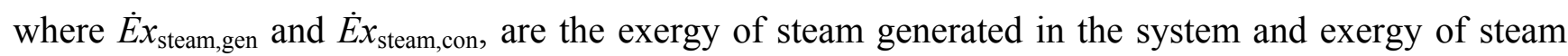
consumed in the system, respectively, $M W_{\text {th }} ; \dot{M}_{\text {steam }}$ is mass flow rate of steam, $\mathrm{kg} / \mathrm{s} ; h$ and $h_{0}$ are specific enthalpy of steam at actual and environmental conditions, $\mathrm{MJ} / \mathrm{kg} ; T$ and $T_{0}$ are the actual temperatures of steam and the environment, $\mathrm{K}$. The actual average environmental condition of the site is assumed 1 bar and $20{ }^{\circ} \mathrm{C}$ in this study. The energy efficiency has been calculated using a conventional method, and the following equation has been derived:

$$
\eta_{e n}=\left(\dot{M}_{\mathrm{pg}} \times L H V_{\mathrm{pg}}+\dot{Q}_{\text {steam,exp }}\right) /\left(\dot{M}_{\text {biom }} \times L H V_{\text {biom }}+\dot{M}_{\text {fuel }} \times L H V_{\text {fuel }}+\dot{Q}_{\text {steam,imp }}\right)
$$

\section{Results and Discussion}

The proposed model has been solved in the UniSim Design and the results are presented in four sections: (i) The simulation on DFB gasification and model validation with the experimental data from the pilot scale DFB gasification system; (ii) The simulation for effects of gasification condition on DFB gasification yields and the integrated system performance; (iii) The simulation for effects of feed biomass moisture content on the performance of the integrated system and (iv) The simulation on energy and exergy analysis of the integrated system.

\subsection{The Simulation and Model Validation of DFB Biomass Gasification}

The developed DFB gasification model has been solved in UniSim and the simulation results of producer gas composition and its $\mathrm{H}_{2} / \mathrm{CO}$ ratio are compared with the corresponding experimental data reported in [32]. The bed material in the BFB gasifier is olivine which does not show significant catalytic effect. The results are shown in Figure 5 for the effects of gasification temperatures from $750{ }^{\circ} \mathrm{C}$ to $850{ }^{\circ} \mathrm{C}$ and in Figure 6 for the effect of $S / B$ ratio from 0.6 to 1.2. As can be seen in Figure 5 and Figure 6, with increase in gasification temperature, the $\mathrm{H}_{2}$ composition increases significantly while $\mathrm{CO}$ composition decreases. In Figure 5, the simulated results are in close agreement with the experimental data for $\mathrm{H}_{2}$ and $\mathrm{CO}$ compositions while the model predicted $\mathrm{CO}_{2}$ composition of the producer gas is underestimated by about $9 \%$. Also, there are discrepancies between simulation results and experimental data for light hydrocarbon compositions although these discrepancies diminish with increase in the gasification temperature. From Figure 6, the simulated $\mathrm{H}_{2}$ composition is in close agreement with the experimental data, however, there are discrepancies between the simulation and the experimental data for $\mathrm{CO}, \mathrm{CO}_{2}$ and $\mathrm{CH}_{4}$ compositions. The predicted trends of the $\mathrm{CO}$ and $\mathrm{CO}_{2}$ compositions are in agreement with experimental data that $\mathrm{CO}$ composition decreases and $\mathrm{CO}_{2}$ 
composition increases with $S / B$ ratio. While the trend of model simulated $\mathrm{CH}_{4}$ composition is inconsistent with the experimental data reported in [32], the model simulated trends are supported by the data reported in $[35,36]$.

Figure 5. Comparison of the producer gas composition resulted from the simulation with the experimental data [32], $S / B=0.84$.

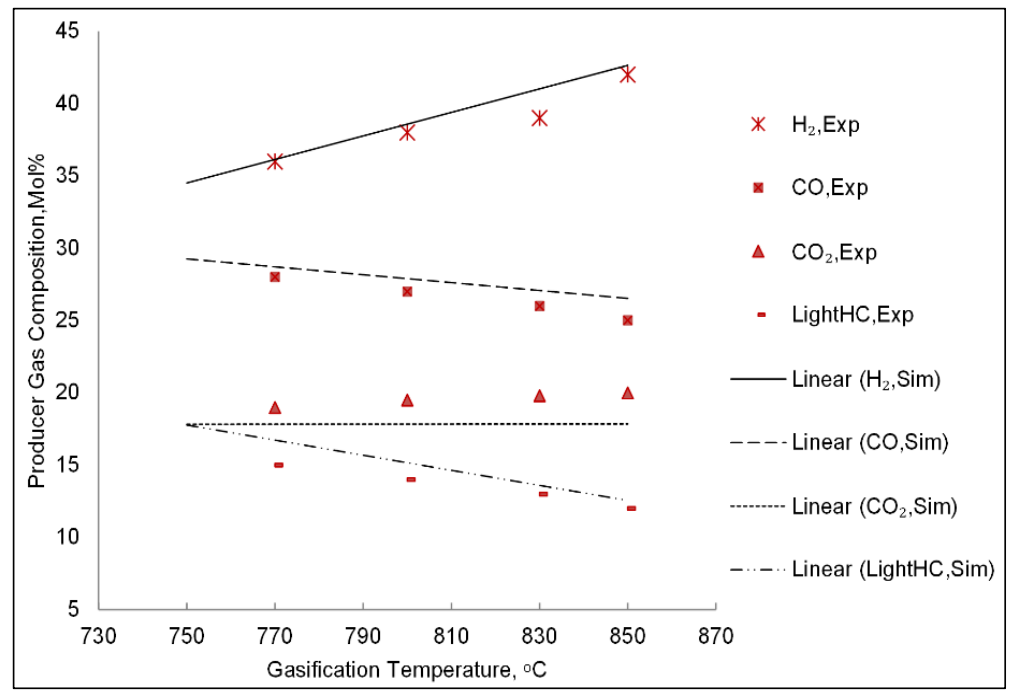

Figure 6. Comparison of the producer gas composition resulted from the simulation with the experimental data [32], $T=850{ }^{\circ} \mathrm{C}$.

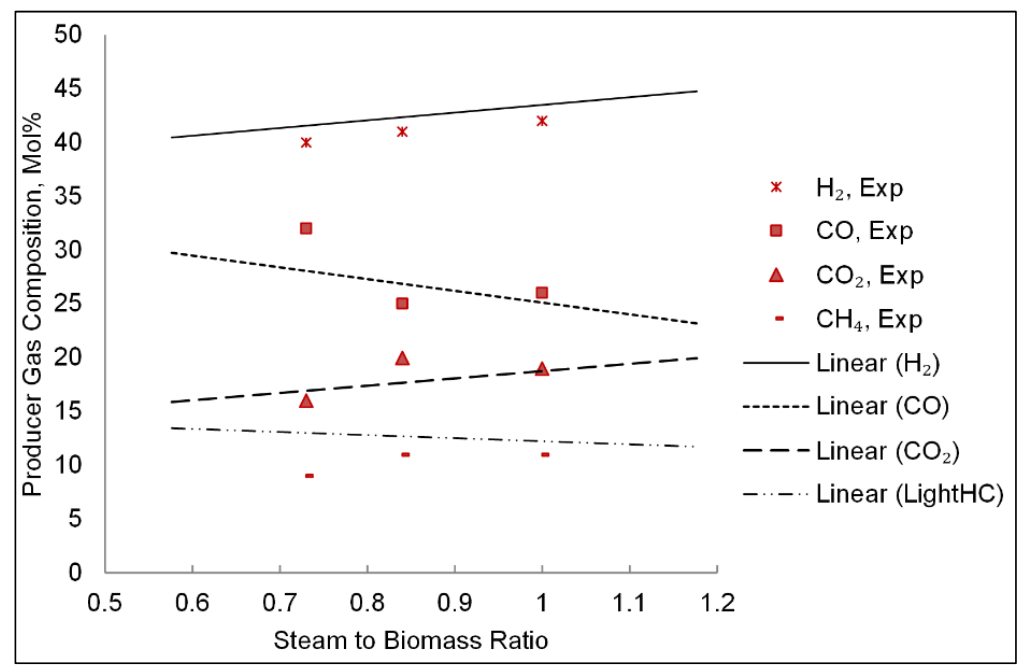

\subsection{Effect of Gasification Conditions on Gasification Performance}

The effect of gasification temperature and $S / B$ ratio on the gasification performance (the yields of producer gas and char, and $\mathrm{H}_{2} / \mathrm{CO}$ ratio of producer gas) has been examined using the developed model and the results are shown in Figure 7 for the effect of gasification temperature and in Figure 8, for the effect of $S / B$ ratio. From the figures, it is found that both the gasification temperature and the $S / B$ ratio have positive impacts on gas yield and $\mathrm{H}_{2} / \mathrm{CO}$ ratio in the producer gas. The simulation results also show that the char yield decreases with gasification temperature and the $S / B$ ratio when more carbon is converted to gas thereby more gas yield. 
However, as can be seen in Figures 7 and 8, the gasification temperature has more significant effect than the $S / B$ ratio on the gas yield. Therefore, increasing the temperature is more effective on char-gas reactions than injecting more steam to the system.

Figure 7. The effect of gasification temperature on the system yields, $S / B=0.84$.

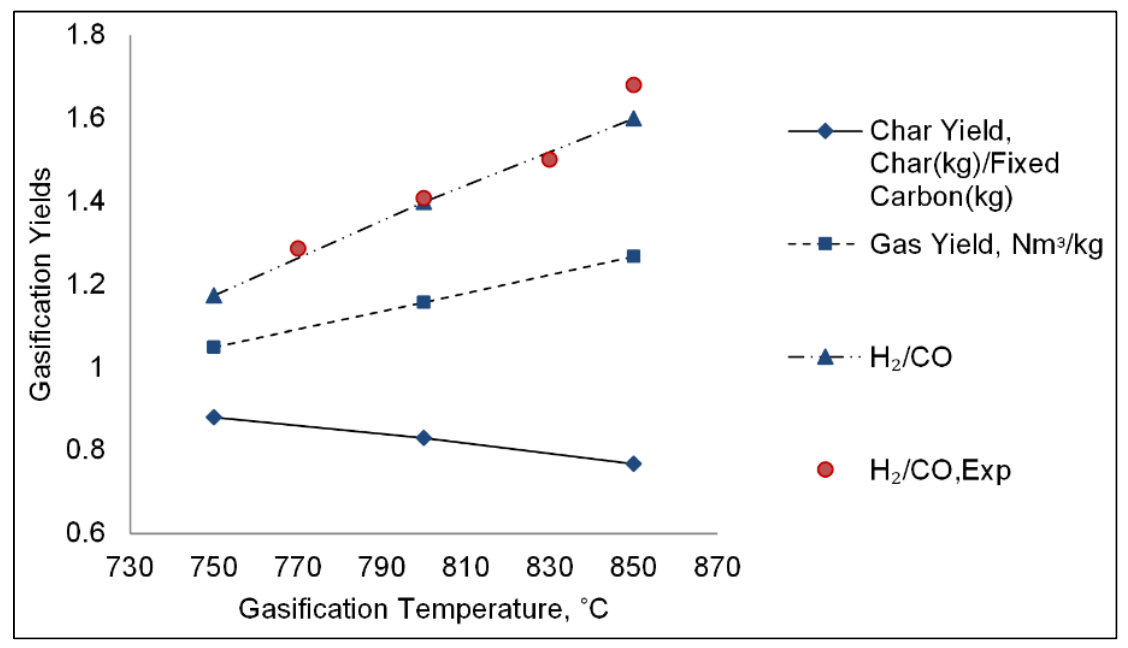

Figure 8. The effect of steam to biomass ratio on the system yields, $T=850{ }^{\circ} \mathrm{C}$.

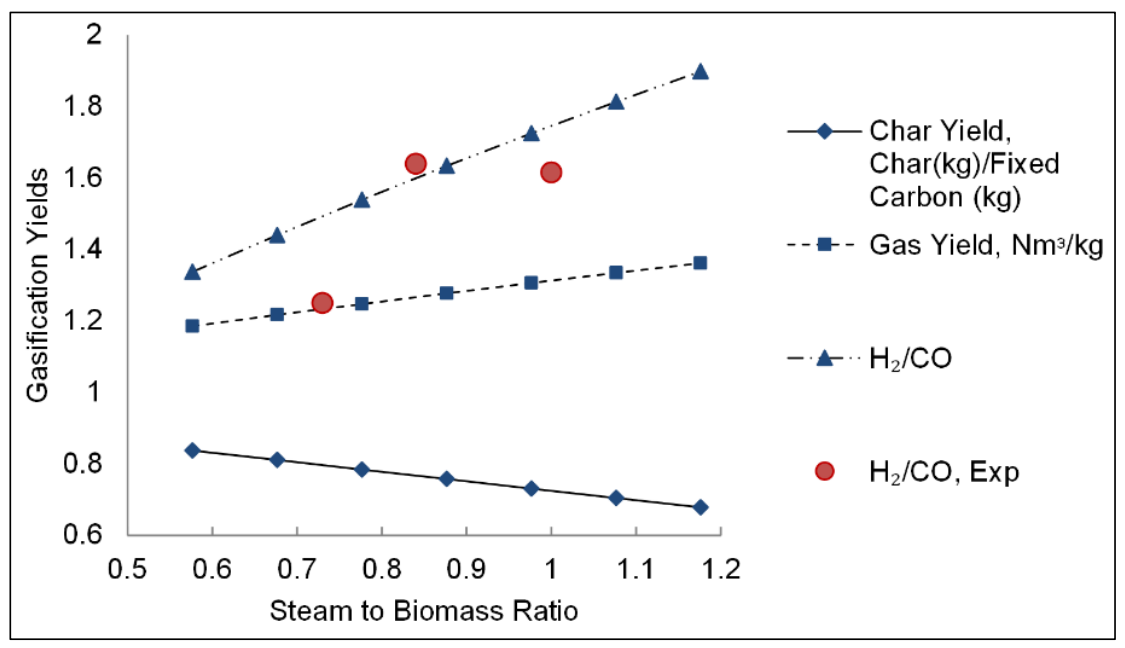

From Figure 8, it is also found that with increase in the $S / B$ ratio the gas yield increases slightly but the $\mathrm{H}_{2} / \mathrm{CO}$ ratio of the produced gas increases more substantially. In fact, both the gasification temperature and $S / B$ ratio favor the steam-gas shift reaction towards hydrogen production according to Le Chatelier's principle, which results in higher $\mathrm{H}_{2} / \mathrm{CO}$ ratio. The experimental data for $\mathrm{H}_{2} / \mathrm{CO}$ ratio at different gasification temperatures and $S / B$ ratios reported in [32] are also shown in Figure 7 and Figure 8, respectively. As can be seen from the figures, although the simulation results are in good agreement with the experimental data for $\mathrm{H}_{2} / \mathrm{CO}$ ratio at different temperatures, there are discrepancies for $\mathrm{H}_{2} / \mathrm{CO}$ ratio at different $S / B$ ratios.

It is predicted by the model that at $S / B$ ratio of 1.2 and gasification temperature of $850{ }^{\circ} \mathrm{C}$, the $\mathrm{H}_{2} / \mathrm{CO}$ ratio of around 1.9 can be achievable which is suitable for FT liquid fuel synthesis. However, the experimental data in [32] shows a slight decrease in $\mathrm{H}_{2} / \mathrm{CO}$ ratio with increase in $S / B$ ratio from 0.84 to 1 while in [36] it shows an increase. 


\subsection{Effect of Excessive Fuel and Air Supply}

The energy requirement of the BFB gasification reactor is provided by the combustion of char and excessive fuel in the FFB reactor. In order to achieve a higher gasification temperature, more excessive fuel and air are needed at the given biomass feeding rate. The model simulation results on excessive fuel requirement at different gasification conditions (temperature and $S / B$ ratio) are shown in Figure 9. In the figure, $\omega$ is the ratio of excessive fuel energy flow to the biomass energy flow as defined in Equation (23). As the char yield declines by increasing both gasification temperature and $S / B$ ratio, more excessive fuel supply is required to the FFB reactor to provide the heat for the gasification. However, at gasification temperature of $800{ }^{\circ} \mathrm{C}$ and steam to biomass ratio between 0.6 and 0.7 , the system does not require excessive fuel supply while the system's fuel requirement dramatically escalates with further increase in the $S / B$ ratio or increase in the gasification temperature.

The air fuel equivalent ratio $(\lambda)$ decreases by increasing the excessive fuel supply to the system. For compensating this reduction in $\lambda$, the excessive air supply to the system is required. However, as is shown in Figure 10, by increasing the air supply to the system, the excessive fuel requirement dramatically escalates which results in modest increase in air fuel equivalent ratio.

Figure 9. The excessive fuel requirement of the system versus $S / B$ ratio.

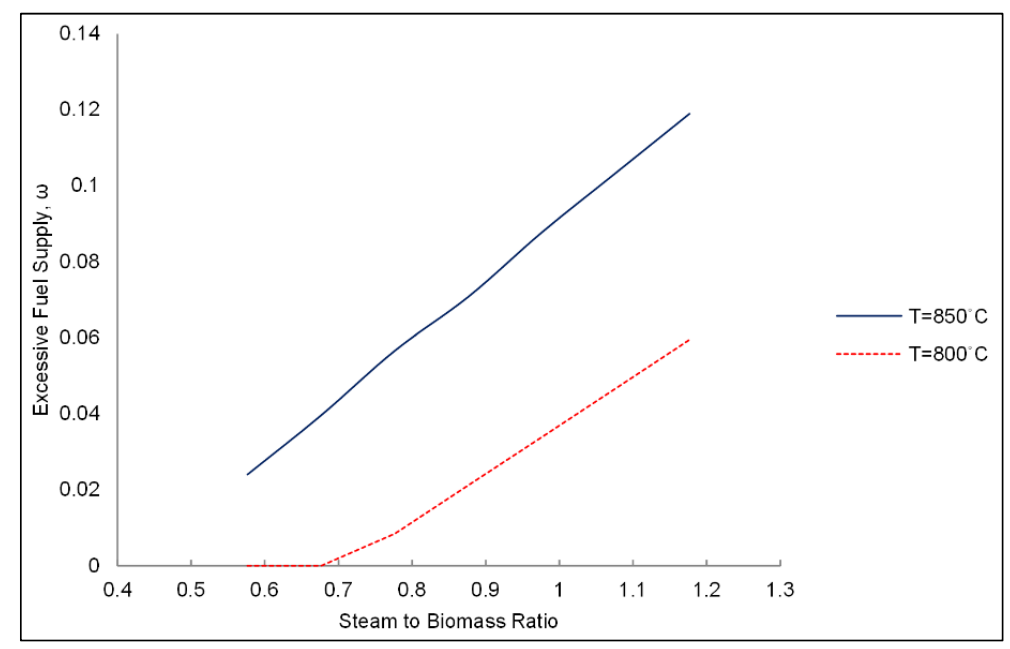

Figure 10. The effect of excessive air supply (air flow/initial air flow) on excessive fuel requirement, $\omega$, and air fuel equivalent ratio, $\lambda . T=850^{\circ} \mathrm{C}$ and $S / B=0.84$.

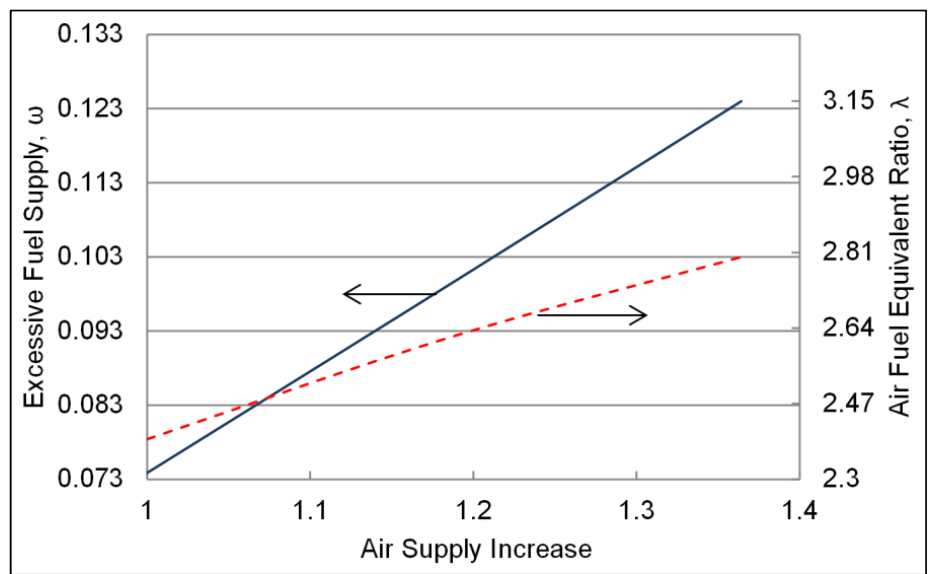




\subsection{The Effect of Feed Biomass Moisture Content on System Performance}

As is shown in Figure 11, with increase in feed biomass moisture content, more energy is needed for drying and thus hotter flue gas is required at a given air supply flow rate or more air is supplied. By increasing the air supply to the FFB reactor thereby flue gas flow rate, the flue gas temperature for biomass drying can be decreased although more excessive fuel has to be supplied to the FFB reactor as well. However, as is shown in Figure 12, with increase in air supply, more steam is generated due to the increase in excessive fuel.

Figure 11. The effect of feed moisture content on the flue gas temperature required for drying, $T=850^{\circ} \mathrm{C}$ and $S / B=0.84$.

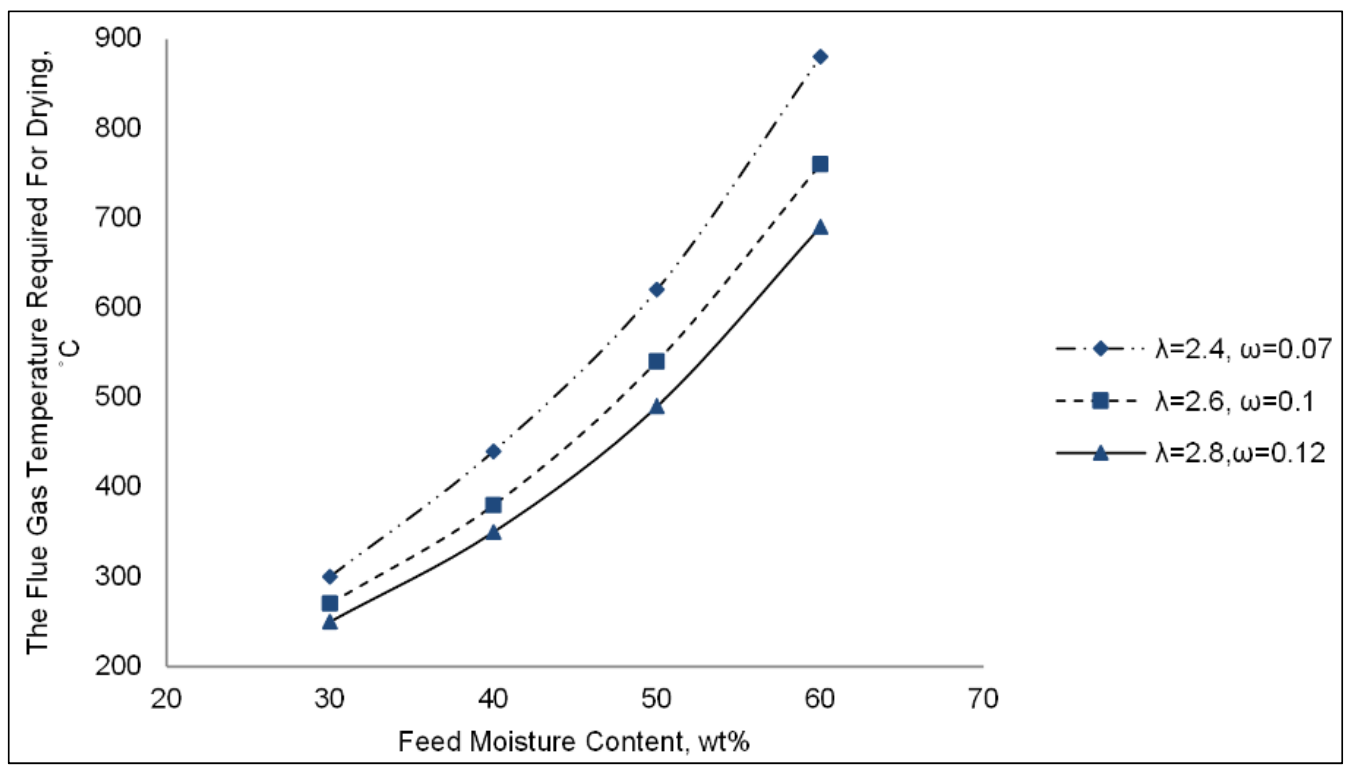

Figure 12. The effect of feed moisture content on the steam generated in the system, $T=850^{\circ} \mathrm{C}$ and $S / B=0.84$.

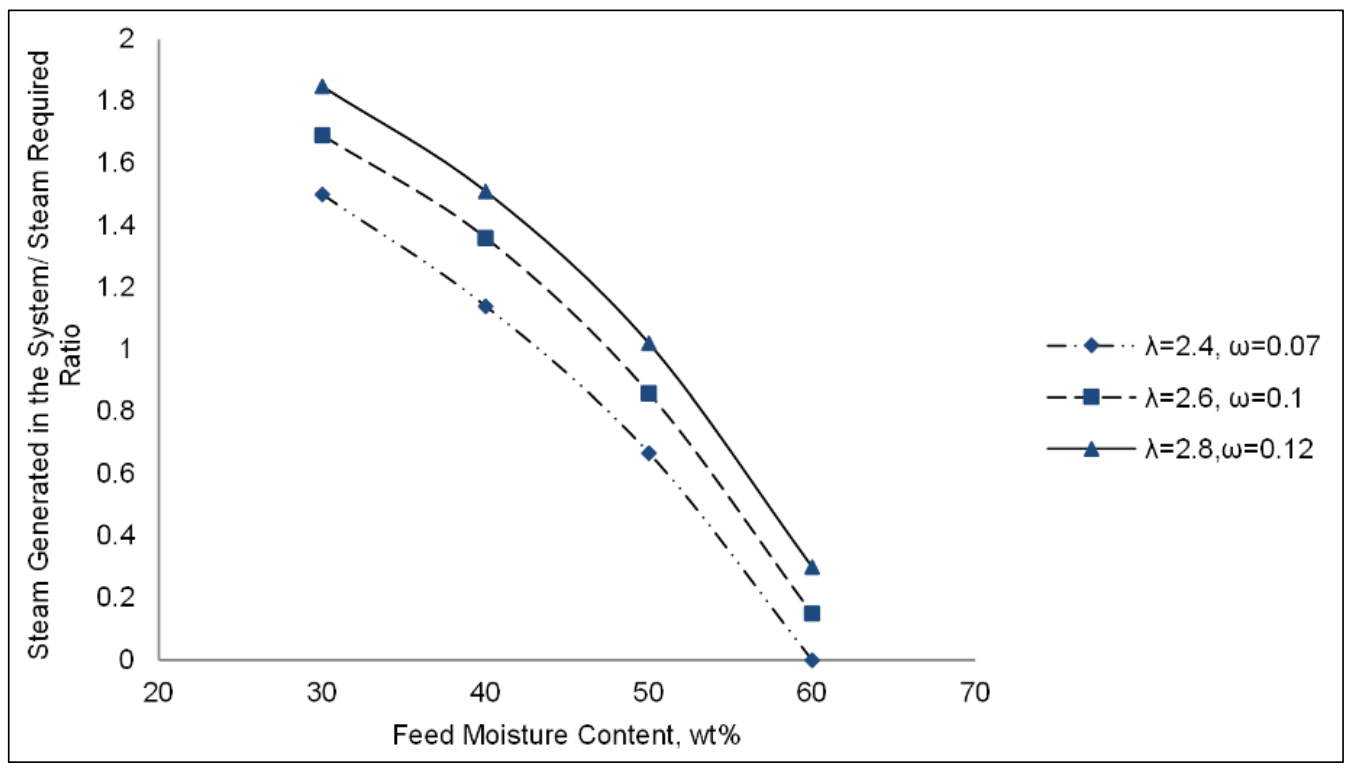




\subsection{The Energy and Exergy Analysis of the System}

The developed model has been used to examine the effect of feed biomass moisture content, air supply and fuel supply on energy and exergy efficiencies of the system and the results are shown in Figure 13 for gasification temperature of $850^{\circ} \mathrm{C}$ and $S / B$ ratio of 0.84 . From the figure, it can be found that with increase in the feed biomass moisture content, the energy efficiency decreases dramatically while exergy efficiency declines slightly. As the feed moisture content increases, more flue gas heat is recovered for drying; therefore, less steam is generated in the system resulting in more steam import. As more steam is imported to the system, the energy efficiency of the system decreases dramatically while the exergy efficiency is less dependent on the amount of steam imported to the system as the exergy value of steam is much less than its energy value.

Figure 13. The effect of feed moisture content on the energy and exergy efficiencies of the system, $T=850{ }^{\circ} \mathrm{C}$ and $S / B=0.84$.

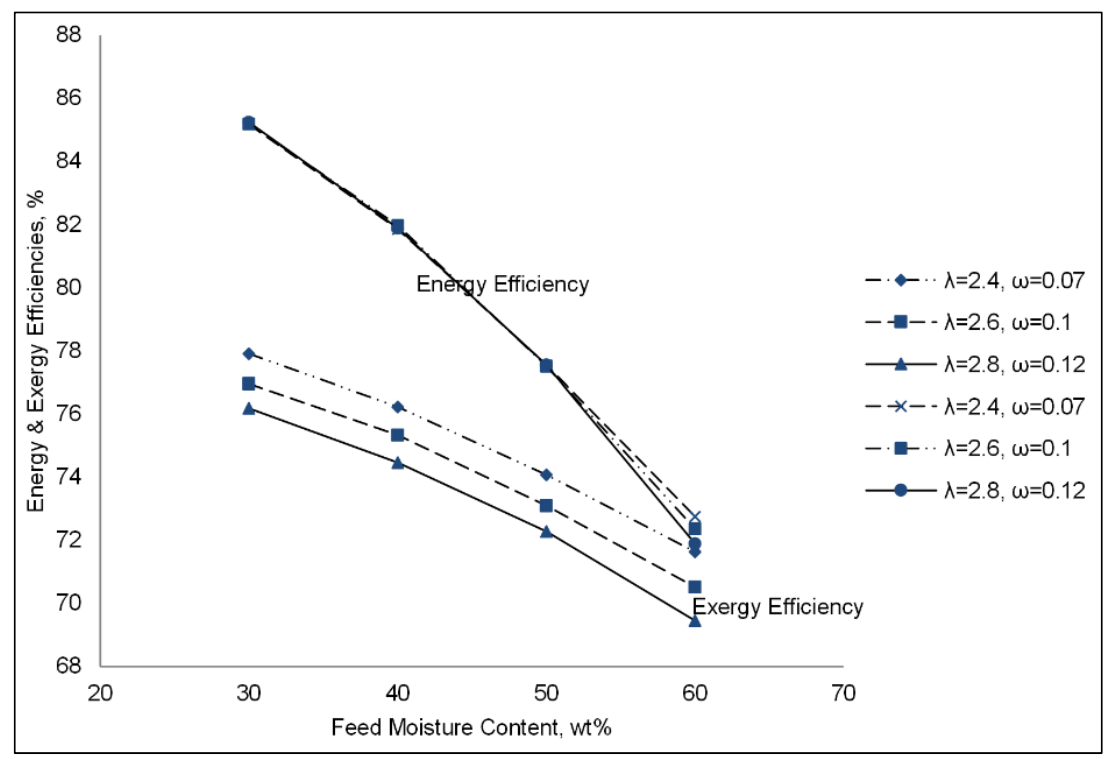

From Figure 13, it is also found that the energy efficiency of the system does not change remarkably by increasing the air and fuel supplied to the system while the exergy efficiency changes significantly. As the air supply to the FFB reactor increases, the excessive fuel requirement of the system increases resulting in higher flue gas flow rate from the FFB reactor. As flue gas flow rate increases, more heat is recovered for steam generation at a given biomass moisture content. Therefore, with more excessive fuel consumption in the system, more steam is generated at the equivalent energy content. However, the exergy possessed by the extra steam generated in the system is less than the exergy of extra excessive fuel since the exergy value of fuel is much higher than exergy value of the steam. Therefore, the exergy efficiency of the system decreases by increasing the air supply to the system while energy efficiency remains unchanged.

The only exhaust stream from the integrated biomass drying and gasification system is the exhaust gas from the rotary dryer. The effect of feed biomass moisture content on energy and exergy losses by the exhaust gas is shown in Figure 14. As can be seen from the figure, although the energy loss of exhaust gas increases dramatically with increase in the feed biomass moisture content, the exergy loss 
is less affected. The energy loss through exhaust gas increases with feed biomass moisture content as its flow rate increases with more water evaporation. However, its exergy slightly changes as its temperature is kept almost constant with increase in feed biomass moisture content. In the drying model, the inlet condition changes while exhaust gas temperature and target moisture content of biomass are constant. Comparing Figure 13 with Figure 14, it is concluded that exhaust gas is the main reason for the energy loss in the system while it has minor impact on exergy loss.

Figure 14. The effect of feed moisture content on energy and exergy losses through waste product in the integrated system, $T=850{ }^{\circ} \mathrm{C}, S / B=0.85$.

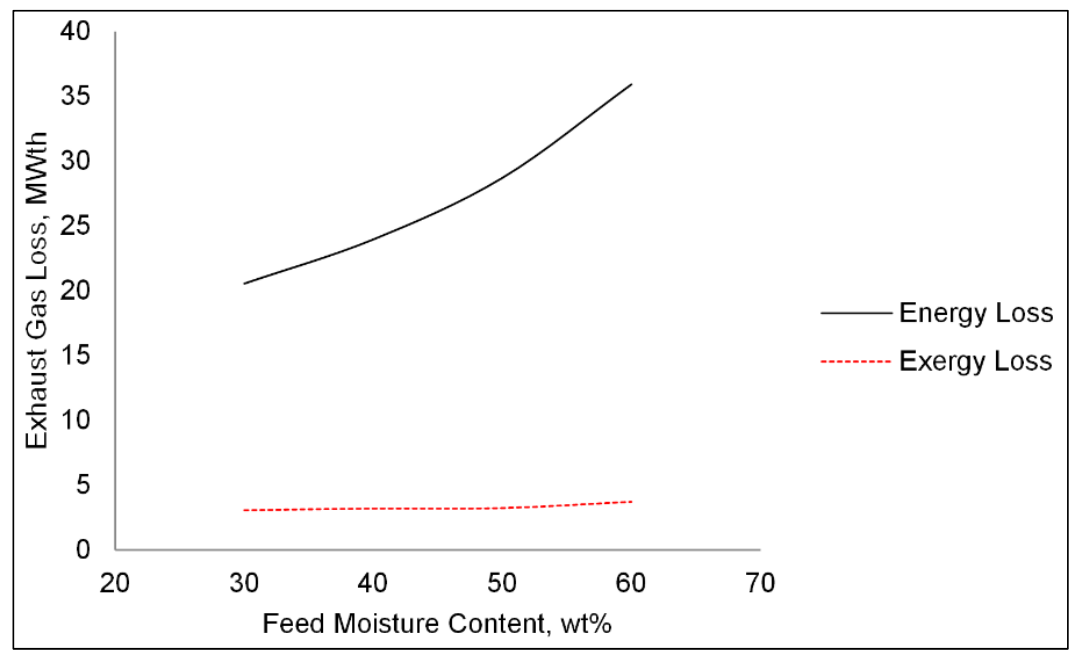

The exhaust stream of flue gas and the irreversibility of unit operations are two sources of exergy loss although the irreversibility of different unit operations is the major contributor to the exergy loss of the system (internal exergy loss). The distribution of different unit operations in internal exergy loss of the system is shown in Figure 15 at different feed biomass moisture content.

Figure 15. The exergy losses of different unit operations in the system, $T=850{ }^{\circ} \mathrm{C}$ and $S / B=0.84$.

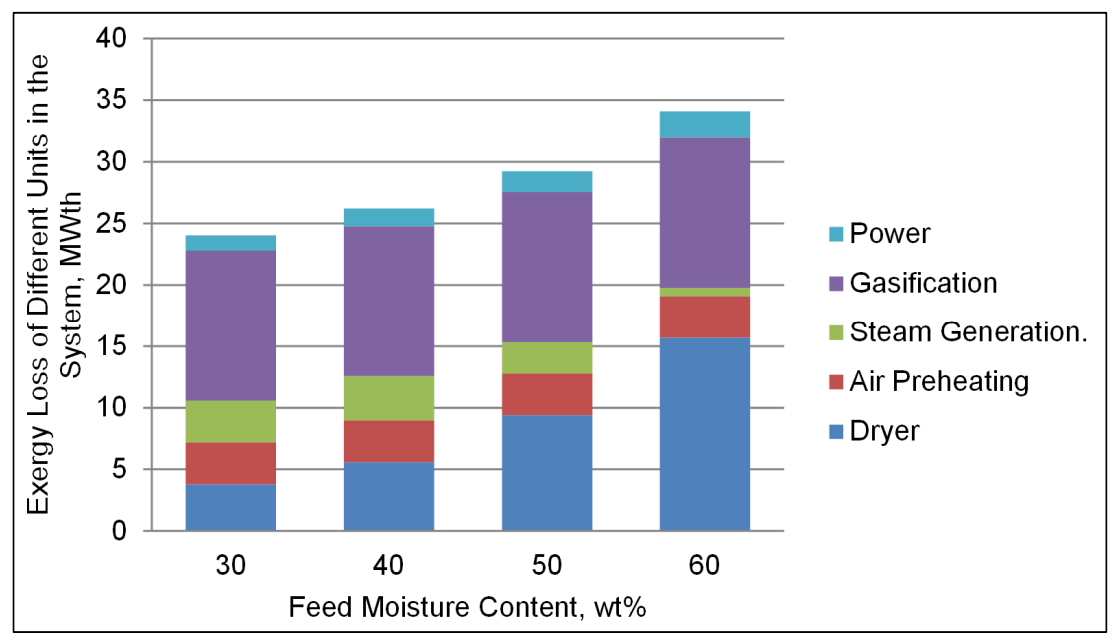

The total exergy loss by the system increases significantly by increasing the feed biomass moisture content. Gasification is the main source of irreversibility in the system which is in agreement with findings of Vitasari et al. [11]. The exergy loss due to the drying is insignificant at low feed biomass 
moisture contents of below $30 \%$ which is also in line with the findings of Vitasari et al. [11]. However, the exergy loss increases with feed biomass moisture contents dramatically and the exergy loss from drying is higher than the gasification with feed biomass moisture content is at $50 \%$ or higher. Exergy loss due to steam generation decreases considerably by increasing the feed biomass moisture content.

\section{Conclusions}

An integrated system model for dual fluidized bed (DFB) gasification and rotary dryer has been developed in UniSim simulation environment. Flue gas from the fast fluidized bed (FFB) reactor is employed for biomass drying.

The DFB gasification model results are in good agreement with the experimental data. Both gasification temperature and $S / B$ ratio favor the gas yield and $\mathrm{H}_{2} / \mathrm{CO}$ ratio of the producer gas. Increasing the gasification temperature is more effective on gas yield while increasing $S / B$ ratio is more effective on $\mathrm{H}_{2} / \mathrm{CO}$ ratio. $\mathrm{A} \mathrm{H}_{2} / \mathrm{CO}$ ratio of 1.9 that is close to the requirement of $\mathrm{FT}$ synthesis can be achieved at $850^{\circ} \mathrm{C}$ and $S / B$ of 1.2 .

Increase of air supply to the DFB gasification is more suitable for drying of biomass with higher moisture content because more flue gas is required, but flue gas with a lower temperature can be employed in the biomass dryer. However, with feed moisture content increase, more air to the FFB reactor is required and more excess fuel is needed for keeping the constant flue gas temperature in the dryer. As a result, more steam is generated with higher flue gas rate and the energy efficiency is less affected. In contrast, exergy efficiency decreases as the exergy of steam generated in the system is much less than the exergy value of the excessive fuel.

The energy efficiency decreases dramatically by increasing the biomass feed moisture content as more heat is spent on biomass drying. The heat loss through dryer's exhaust gas is the major contributor of energy loss in the system. In contrast, the exergy efficiency slightly decreases as the exergy loss through dryer's exhaust gas is insignificant. The thermodynamic irreversibility of unit operations is the major source of exergy loss with gasification as the major player. However, at feed biomass moisture content more than $50 \%$, biomass drying becomes a major source of exergy loss in the system as well.

\section{Acknowledgments}

This study is part of the research program of Biomass to Syngas and Liquid Fuels funded by the Ministry of Business, Innovation \& Employment, New Zealand.

\section{Author Contributions}

Nargess Puladian has established the system model and prepared the draft paper as part of her study on feasibility study of biomass to syngas and liquid fuels. Shusheng Pang guided the research direction and checked the model establishment. Jingge $\mathrm{Li}$ made valuable contributions on the model development and writing improvement. 


\section{Conflicts of Interest}

The authors declare there are no conflicts of interest.

\section{References}

1. Saw, W.; Pang, S. Influence of mean gas residence time in the bubbling fluidised bed on the performance of a 100-kW dual fluidised bed steam gasifier. Biomass Convers. Bioref. 2012, 2, 197-205.

2. Hofbauer, H.; Rauch, R.; Loeffler, G.; Kaiser, S.; Fercher, E.; Tremmel, H. Six years experience with the FICFB-Gasification process. In Proceedings of the 12th European Biomass Conference, Amsterdam, The Netherlands, 17-21 June 2002.

3. Hofbauer, H.; Rauch, R.; Bosch, K.; Koch, R.; Aichernig, C. CHP Plant Güssing-A Success Story. In Pyrolysis and Gasification of Biomass and Waste; CPL Press: Newbury, NH, USA, 2003.

4. Saw, W.; McKinnon, H.; Gilmour, I.; Pang, S. Production of hydrogen-rich syngas from steam gasification of blend of biosolids and wood using a dual fluidised bed gasifier. Fuel 2012, 93, 473-478.

5. Van der Drift, A.; van Doorn, J.; Vermeulen, J.W. Ten residual biomass fuels for circulating fluidized-bed gasification. Biomass Bioenergy 2001, 20, 45-56.

6. Pang, S.; Mujumdar, A.S. Drying of woody biomass: Drying technologies for an integrated bio-energy plant. Dry. Technol. 2010, 28, 690-801.

7. Xu, Q.; Pang, S. Mathematical modeling of rotary drying of woody biomass. Dry. Technol. 2008, 26, 1344-1350.

8. Begum, S.; Rasul, M.G.; Akbar, D.; Ramzan, N. Performance analysis of an integrated fixed bed gasifier model for different biomass feedstocks. Energies 2013, 6, 6508-6524.

9. Begum, S.; Rasul, M.G.; Akbar, D.; Cork, D. An experimental and numerical investigation of fluidized bed gasification of solid waste. Energies 2014, 7, 43-61.

10. Holmberg, H.; Ahtila, P. Evaluation of energy efficiency in biofuel drying by means of energy and exergy analyses. Appl. Therm. Eng. 2005, 25, 3115-3128.

11. Vitasari, C.R.; Jurascik, M.; Ptasinski, K.J. Exergy analysis of biomass-to-synthetic natural gas (SNG) process via indirect gasification of various biomass feedstock. Energy 2011, 36, 3825-3837.

12. Aspen Process Flowsheet Simulation Model of a Battelle Biomass-Based Gasification, Fischer-Tropsch Liquefaction and Combined-Cycle Power Plant; Technical Report No. DE-AC22-93PC91029-16; Pittsburgh Energy Technology Center: Pittsburg, PA, USA, 1998.

13. Tijmensen, M.J.A.; Faaij, A.P.C.; Hamelinck, C.N.; van Hardeveld, M.R.M. Exploration of the possibilities for production of Fischer Tropsch liquids and power via biomass gasification. Biomass Bioenergy 2002, 23, 129-152.

14. Swanson, R.M.; Platon, A.; Satrio, J.A.; Brown, R.C. Techno-economic analysis of biomass-to-liquids production based on gasification. Fuel 2010, 89, S11-S19.

15. Marinos-Kouris, D.; Maroulis, Z.B.; Kiranoudis, C.T. Modeling, simulation and design of convective industrial dryers. Dry. Technol. 1998, 16, 993-1026. 
16. Schuster, G.; Löffler, G.; Weigl, K.; Hofbauer, H. Biomass steam gasification, An extensive parametric modeling study. Bioresour. Technol. 2001, 77, 71-79.

17. Rutherford, J. Heat and Power Applications of Advanced Biomass Gasifiers in New Zealand's Wood Industry. Master's Thesis, University of Canterbury: Christchurch, New Zealand, 2006; p. 114.

18. Jarungthammachote, S.; Dutta, A. Thermodynamic equilibrium model and second law analysis of a downdraft waste gasifier. Energy 2007, 32, 1660-1669.

19. Ngo, S.I.; Nguyena, T.D.B.; Lim, Y.; Song, B.-H.; Lee, U.-D.; Choi, Y.-T.; Song, J.-H. Performance evaluation for dual circulating fluidized-bed steam gasifier of biomass using quasi-equilibrium three-stage gasification model. Appl. Energy 2011, 88, 5208-5220.

20. Nguyen, T.D.B.; Ngoa, S.I.; Lim, Y.-I.; Lee, J.W.; Lee, U.-D.; Song, B.-H. Three-stage steady-state model for biomass gasification in a dual circulating fluidized-bed. Energy Convers. Manag. 2012, 54, 100-112.

21. Proll, T.; Hofbauer, $\mathrm{H} . \mathrm{H}_{2}$ rich syngas by selective $\mathrm{CO}_{2}$ removal from biomass gasification in a dual fluidized bed system-Process modelling approach. Fuel Process. Technol. 2008, 89, 1207-1217.

22. Glass, S.V.; Zelinka, S.L. Moisture relations and physical properties of wood. In Handbook of Wood: Wood as an Engineering Material; Forest Products Laboratory: Madison, WI, USA, 1999.

23. Boerrigter, H.; Calis, H.P.; Slort, D.J.; Bodenstaff, H. Gas cleaning for integrated biomass gasification and Fischer-Tropsch systems. Experimental demonstration of two BG-FT systems. In proceedings of the 2nd Word Conference and Technology Exhibition on Biomass for Energy and Climate Protection, Rome, Italy, 10-14 May 2014.

24. Iguaz, A.; Esnoz, A.; Martínez, G.; López, A.; Vírseda, P. Mathematical modelling and simulation for the drying process of vegetable wholesale by-products in a rotary dryer. J. Food Eng. 2003, 59, 151-160.

25. Meza, J.; Gil, A.; Cortés, C.; González, A. Drying costs of woody biomass in a semi-industrial experimental rotary dryer. In Proceedings of the 16th European Conference \& Exhibition on Biomass for Energy, Biomass Resources, Valecia, Spain, 2-6 June 2008.

26. Saeman, W.C.; Mitchell, T.R. Analysis of Rotary Dryer a Cooler Performance. Chem. Eng. Prog. 1954, 50, 467-475.

27. McCabe, W.L.; Smith, J.C.; Harriott, P. Solid drying. In Unit Opeartions of Chemical Engineering; McGraw-Hill: Boston, MA, USA, 2001.

28. Franco, C.; Pinto, F.; Gulyurtlu, I.; Cabrita, I. The study of reactions influencing the biomass steam gasification process. Fuel 2003, 82, 835-842.

29. Sadaka, S.S.; Ghaly, A.E.; Sabbah, M.A. Two phase biomass air-steam gasification model for fluidized bed reactors: Part I-model development. Biomass Bioenergy 2002, 22, 439-462.

30. Fagbemi, L.; Khezami, L.; Capart, R. Pyrolysis products from different biomasses: Application to the thermal cracking of tar. Appl. Energy 2001, 69, 293-306.

31. Aigner, I.; Wolfesberger, U.; Hofbauer, H. Tar content and composition in producer gas of fluidized bed gasification and low temperature pyrolysis of straw and wood-influence of temperature. In Proceedings of the International Conference on Polygeneration Strategies, Vienna, Austria, 3-5 September 2013. 
32. Koppatz, S.; Pfeifer, C.; Hofbauer, H. Comparison of the performance behaviour of silica sand and olivine in a dual fluidised bed reactor system for steam gasification of biomass at pilot plant scale. Chem. Eng. J. 2011, 175, 468-483.

33. Yoshida, H.; Kiyono, F.; Tajima, H.; Yamasaki, A.; Ogasawara, K.; Masuyama, T. Two-stage equilibrium model for a coal gasifier to predict the accurate carbon conversion in hydrogen production. Fuel 2008, 87, 2186-2193.

34. Nguyen, T.D.B.; Lim, Y.-I.; Song, B.-H.; Kim, S.-M.; Joo, Y.-J.; Ahn, D.-H. Two-stage equilibrium model applicable to the wide range of operating conditions in entrained-flow coal gasifiers. Fuel 2010, 89, 3901-3910.

35. Herguido, J.; Corella, J.; Gonzalez-Saiz, J. Steam gasification of lignocellulosic residues in a fluidized bed at a small pilot scale. Effect of the type of feedstock. Ind. Eng. Chem. Res. 1992, 31, 1274-1282.

36. Wei, L.; Xu, S.; Zhang, L.; Liu, C.; Zhu, H.; Liu, S. Steam gasification of biomass for hydrogen-rich gas in a free-fall reactor. Int. J. Hydrog. Energy 2007, 32, $24-31$.

37. Sohel, M.I.; Jack, M.W. Thermodynamic analysis of lignocellulosic biofuel production via a biochemical process: Guiding technology selection and research focus. Bioresour. Technol. 2011, $102,2617-2622$.

38. Nikulshin, V.; Wu, C.; Nikulshina, V. Exergy Efficiency Calculation of Energy Intensive Systems by Graphs. Exergy Int. J. 2002, 2, 78-86.

39. Prins, M.J.; Ptasinski, K.J.; Janssen, F.J.J.G. Exergetic optimisation of a production process of Fischer-Tropsch fuels from biomass. Fuel Process. Technol. 2005, 86, 375-389.

40. Szargut, J. Exergy Method: Technical and Ecological Applications; WIT Press: Sothhampton, UK, 2005.

(C) 2014 by the authors; licensee MDPI, Basel, Switzerland. This article is an open access article distributed under the terms and conditions of the Creative Commons Attribution license (http://creativecommons.org/licenses/by/3.0/). 